\title{
HIGH-PERFORMANCE LIQUID CHROMATOGRAPHY ANALYSIS FOR $\alpha$-CYPERONE AND NOOTKATONE FROM THE TUBER OF NUTSEDGE (Cyperus rotundus L.) IN THE TROPICS
}

\author{
Ferdhi Isnan Nuryana, M. A. Chozin* and Dwi Guntoro \\ Department of Agronomy and Horticulture, Faculty of Agriculture, IPB University, Bogor \\ 16680, (West Java) Indonesia \\ *E-mail : ma_chozin@yahoo.com
}

\begin{abstract}
Two primary compounds from the sesquiterpene group contained in nutsedge's tuber, $\alpha$-cyperone and nootkatone are related to its benefits as herbal medicine and natural pesticides. This research was conducted to analyze the content of $\alpha$-cyperone and nootkatone at three different part of the tuber (whole-tuber, peeled-tuber, and tuber's peel) so that it indicates the level of activity from these parts of nutsedge tuber in the tropics. The ethanolic extracts were analyzed using high-performance liquid chromatography (HPLC) equipped with C18 column, acetonitrile and aquabidestillata $(65: 35)$ as a mobile phase and PDA detection at $254 \mathrm{~nm}$. The analysis showed the results that the highest content of $\alpha$-cyperone was on the whole-tuber $1.074 \%$, followed by peeled-tuber $0.736 \%$ and tuber's peel $0.202 \%$. Nootkatone was not found in this nutsedge's tuber.
\end{abstract}

Keywords: Sesquiterpenes, secondary metabolites, HPLC.

(C) RASĀYAN. All rights reserved

\section{INTRODUCTION}

Nutsedge (Cyperus rotundus) is a weed that is frequently found in agricultural land in Indonesia ${ }^{1,2}$. The tuber of nutsedge has many potentials to be utilized ${ }^{3}$. Some of the well-known human health's benefits are as anti-inflammatory, antidiabetic, antimicrobial and others ${ }^{4}$. In addition to its many benefits in herbal medicine, it also has advantages in agriculture ${ }^{5}$. This is an opportunity to make nutsedge as a material for natural pesticides ${ }^{6}$. The secondary metabolites contained in its tuber has allelopathic effects so that it can inhibit the germination of seeds ${ }^{7}$. Some of these benefits are influenced by the active compound of secondary metabolites in nutsedge tuber which are dominated by sesquiterpene ${ }^{8}$. Sesquiterpene is an oillike compound, and it is the highest content in essential oils ${ }^{9,10}$. The dominant sesquiterpene compounds in nutsedges are $\alpha$-cyperone and nootkatone. HPLC analysis for these two compounds and several other sesquiterpene compounds has been carried out, but the nutsedge analyzed mostly comes from the subtropical region. This study aims to determine the content of $\alpha$-cyperone and nootkatone on the different part of nutsedge tuber from the tropical areas.

\section{EXPERIMENTAL}

\section{Material}

The tuber of nutsedge from Babakan Experimental Station, IPB University, Bogor, Indonesia (-6.560753, 106.734604) was macerated with 96\% ethanol. $\alpha$-Cyperone standard (ALB Materials Inc.), nootkatone standard (ALB Materials Inc.), methanol pro-HPLC (Merck), acetonitrile (Merck), aquabidestillata (Trop BRC Laboratories).

\section{Extraction of the Different Part of Tuber}

The extract was prepared by soaking $300 \mathrm{~g}$ whole-tuber powder with $1.50 \mathrm{~L}$ of $90 \% \mathrm{EtOH}, 60 \mathrm{~g}$ tuberpeeled powder with $0.3 \mathrm{~L}$ of $90 \% \mathrm{EtOH}$, and $40 \mathrm{~g}$ peel of tuber powder with $0.2 \mathrm{~L}$ of $90 \% \mathrm{EtOH}$ for 24

Rasayan J. Chem., 12(1), 360-365(2019)

http://dx.doi.org/10.31788/RJC.2019.1215024

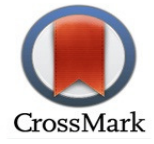


hours repeated 3 times. Filter paper (Whatman, USA) was used to filtered the extract. Filter results were concentrated in a rotary evaporator (Heidolph Hei-VAP Value, Germany), and stored at $4 \square \mathrm{C}$ until use. The yield was $18.7623 \mathrm{~g}(6.25 \%), 12.7247 \mathrm{~g}(21.21 \%)$, and $3.2258 \mathrm{~g}(8.06 \%)$ respectively.

\section{Preparation of $\alpha$-Cyperone and Nootkatone Standard Solution}

Methanol pro-HPLC (Merck) was used to dissolve $20 \mathrm{mg}$ of $\alpha$-cyperone standard (2000 ppm), and then diluted it to $50 \mathrm{ppm}$. A total of $100 \mathrm{mg}$ of nootkatone standard was dissolved in $10 \mathrm{ml}$ of methanol (10000 ppm), and then diluted it to $100 \mathrm{ppm}$.

\section{Preparation of Sample}

Methanol pro-HPLC (Merck) was used to dissolve the extract of a different part of nutsedge tuber (4000 ppm) and sonicated it for 30 minutes. Syringe filter $0.45 \mu \mathrm{m}$ (Whatman, USA) was used to filter the sample.

\section{Mobile Phase Preparation}

Acetonitrile and aquabidestillata with a ratio of $65: 35$ was filtered with $0.45 \mu \mathrm{m}$ nylon membrane filter (GE Healthcare, UK), then sonicated for 30 minutes.

\section{HPLC Instrumentation}

HPLC (Shimadzu LC-20AD Liquid Chromatography, SPD-M20A Diode Array Detector) was used to analyze the sample, equipped with Shim-pack VP-ODS C18 column (150 mm x $4.6 \mathrm{~mm})$ with $30 \square$ C temperature. Acetonitrile (solvent A) and aquabidestillata (solvent B) was prepared as the mobile phase. The elution conditions were $0-35 \mathrm{~min}$ of $65 \% \mathrm{~A}$ and $35 \% \mathrm{~B}$. The flow rate was $1.0 \mathrm{ml} / \mathrm{min}$. $\alpha$-cyperone and nootkatone were detected at $254 \mathrm{~nm}^{11}$.

\section{Analysis of $\alpha$-Cyperone and Nootkatone in Ethanolic Nutsedge Tuber Extract}

The $50 \mathrm{ppm} \alpha$-cyperone standard solution $(10 \mu \mathrm{l})$, the $100 \mathrm{ppm}$ nootkatone standard solution $(10 \mu \mathrm{l})$ and the ethanolic nutsedge extract solution $(10 \mu \mathrm{l})$ was injected to HPLC. The content $(\%)$ of $\alpha$-cyperone was calculated by measuring the area under the curve with this equation:

$$
\frac{\frac{\text { Sample Area }(\mathrm{mAu})}{\text { Standard Area }(\mathrm{mAu})} \times[\text { Standard }(\mathrm{ppm})] \times \text { Volumetric Flasks Volume }(\mathrm{ml})}{\text { Sample Weight }(\mu \mathrm{g})}
$$

\section{RESULTS AND DISCUSSION}

\section{HPLC Analysis of $\alpha$-Cyperone in Nutsedge Ethanolic Extract}

$\alpha$-cyperone is a compound belongs to the terpene group, precisely the sesquiterpene (C15). The sesquiterpene group is produced through the mevalonic acid pathway. It starts with glycolysis in carbohydrates so that it becomes pyruvic acid then acetyl co-A enters into the pathway of mevalonic acid so that it becomes a sesquiterpene compound such as $\alpha$-cyperone ${ }^{12}$. The chemical structure of $\alpha$-cyperone is as in Fig.-1A.

HPLC with the precise and stable method will give the rugged and robust results ${ }^{13}$. HPLC analysis has been done in different parts of nutsedge tuber, namely whole-tuber, tuber-peeled and peel of tuber. Whole-tuber is the tuber that has been cleansed from the root, tuber-peeled is a whole-tuber that has been peeled off, while the peel of tuber is the waste of whole-tuber to become tuber-peeled. The results of the analysis showed that $\alpha$-cyperone was found in all parts of the tuber shown in Fig.-1C-E. There are differences in the content of the phenolic compound between plant parts mostly found in the tuber ${ }^{14}$. The retention time of the $\alpha$-cyperone standard was 10.400 minutes. The chromatogram of $\alpha$-cyperone standard shown in Fig.-1B. $\alpha$-cyperone in the whole-tuber extract was detected at 10.430 minutes (Fig.$1 \mathrm{C})$, still in the $\alpha$-cyperone standard range of 9.963-11.093 minutes. The $\alpha$-cyperone area in the wholetuber showed a value of $1349131 \mathrm{mAu}$ and had a height of $89423 \mathrm{mAu}$. Based on the calculation using the equation in the method, the content of $\alpha$-cyperone in the whole-tuber ethanolic extract was $0.736 \%$. 
RASĀYAN J. Chem.

Vol. 12 | No. 1 |360 - 365| January - March | 2019

Table-1: Retention Time, Area, Height, Peak start, Peak end, and Content of $\alpha$-Cyperonefrom Standard and Different Part of Nutsedge Tuber

\begin{tabular}{c|c|c|c|c|c|c}
\hline Source of $\alpha$-cyperone & $\begin{array}{c}\text { Ret. Time } \\
(\text { minutes })\end{array}$ & $\begin{array}{c}\text { Area } \\
(\mathrm{mAu})\end{array}$ & $\begin{array}{c}\text { Height } \\
(\mathrm{mAu})\end{array}$ & $\begin{array}{c}\text { Peak Start } \\
(\text { minutes })\end{array}$ & $\begin{array}{c}\text { Peak End } \\
(\text { minutes })\end{array}$ & $\begin{array}{c}\text { The content of } \\
\alpha \text {-cyperone } \\
(\%)\end{array}$ \\
\hline$\alpha$-cyperone standard & 10.400 & 1431853 & 94465 & 9.963 & 11.093 & - \\
\hline$\alpha$-cyperone in whole-tuber & 10.430 & 1349131 & 89423 & 9.973 & 10.688 & 0.736 \\
\hline$\alpha$-cyperone in peeled-tuber & 10.447 & 578703 & 30469 & 9.973 & 10.720 & 1.074 \\
\hline$\alpha$-cyperone in tuber's peel & 10.410 & 286922 & 24910 & 9.867 & 10.677 & 0.202 \\
\hline
\end{tabular}

$\alpha$-cyperone in peeled-tuber detected a peak chromatogram at 10.447 minutes (Fig.-1D), parallel to the peak chromatogram of the $\alpha$-cyperone standard. It was in the range of a-cyperone standards which was 9.963 to 11.093 minutes. The area of $\alpha$-cyperone in the peeled-tuber extract was $578703 \mathrm{mAu}$ and had a height of $30469 \mathrm{mAu}$. With the equation in the method, the content of $\alpha$-cyperone in the peeled-tuber ethanolic extract was $1.074 \%$.

$\alpha$-cyperone on tuber's peel detected a peak of chromatogram at 10.410 minutes (Fig.-1E), parallel to the peak chromatogram of the standard. The area of $\alpha$-cyperone in tuber's peel was $286922 \mathrm{mAu}$ and had a height of $24910 \mathrm{mAu}$. The content of $\alpha$-cyperone in the ethanolic tuber's peel extract was $0.202 \%$.

In essential oils obtained in Iran, the most prominent component was $\alpha$-cyperone with $32.0 \%{ }^{15}$. Whereas the nutsedge essential oil from South Africa with two different places showed that the content of $\alpha$ cyperone in place A $11.0 \%$ while in place B $7.9 \%{ }^{16}$.

Nutsedge essential oil from Brazil showed the $\alpha$-cyperone content of $22.8 \%{ }^{17}$. Nutsedge tuber oil from Tunisia contained $4.5 \%$ of $\alpha$-cyperone ${ }^{18}$. There was a difference in the percentage of $\alpha$-cyperone in essential oils from between subtropical area, especially with tropical regions. This percentage difference is not only caused by differences in accession, but also due to different methods in making essential oils.

\section{HPLC Analysis of Nootkatone in Nutsedge Ethanolic Extract}

Research of $\alpha$-cyperone and nootkatone conducted by Kum in 2017 showed that nootkatone was detected at 9.40 minutes and a-cyperone at 12.40 minutes. Although the analysis method used in this study refers to Kum 2017, the retention time of these two compounds showed the difference in results caused by the column. Kum using C18 Xbridge column and in this study using Shim-pack column.

This study carried out two injection techniques namely single injection and spike injection. Single injection used to determine the retention time of each compound, while spike injection is carried out if the compounds in the extract are not precisely at the same retention time, so it needs to be reconfirmed by mixing the standard with extract. If the spike injection occurs one big peak, the compound shows the target compound, but if two different peaks appear, the compounds detected in the extract are not the target compound.

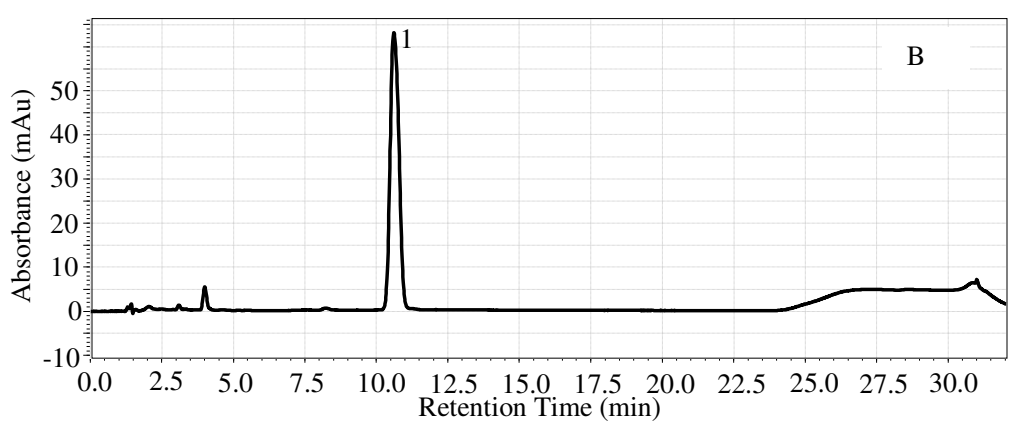

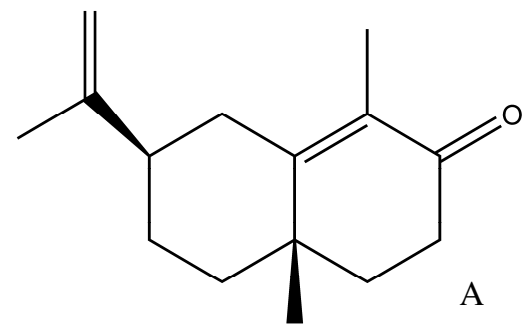

A 
RASĀYAN J. Chem.

Vol. 12 | No. 1 |360 - 365| January - March | 2019
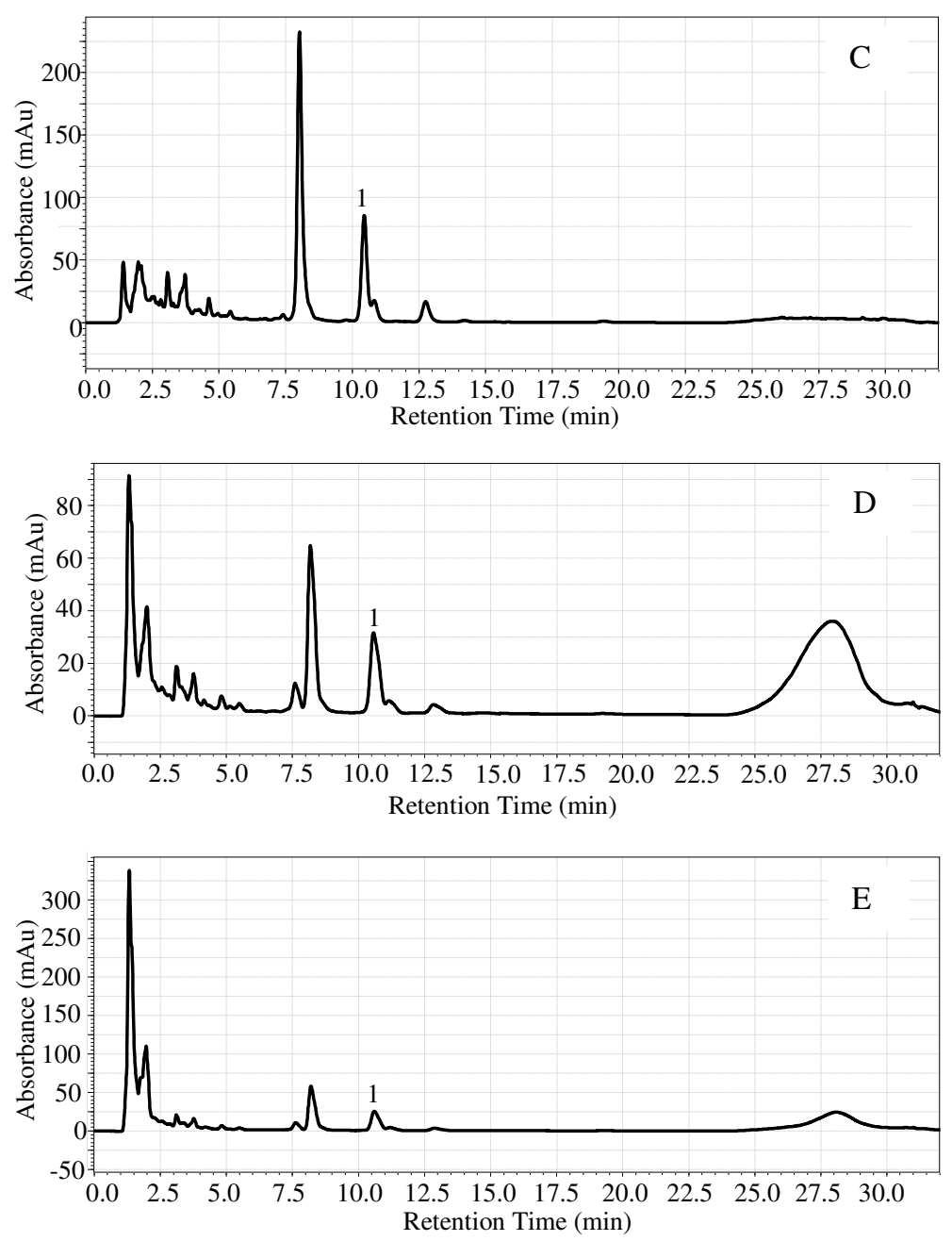

Fig.-1: (A) Chemical Structure of $\alpha$-cyperone; The HPLC Chromatogram of (B) $\alpha$-Cyperone standard; (C) WholeTuber extract; (D) Tuber-peeled extract; (E) Tuber's peel extract; and (1) $\alpha$-Cyperone.

The results showed that the nutsedge tuber in this study does not indicate the presence of nootkatone compounds. In contrast to the results in nutsedge tuber from the subtropics. Nootkatone was found in essential oils of the genera Citrus (Rutaceae), Alpinia (Zingiberaceae) and other Pinales; (Cyperus rotundus) and Vetiver grass (Vetiveria sp. ${ }^{19}$. The absence of nootkatone compounds is relevant to research conducted by Dewi et al. (2017) that there are differences in the content of phenolic compounds between accessions ${ }^{20}$.

Table-2: Retention Time, Area, height, Peak start and Peak end from Nootkatone Standard and Whole-Tuber extract with Single and Spike Injection

\begin{tabular}{c|c|c|c|c|c}
\hline Source of Nootkatone & $\begin{array}{c}\text { Ret. Time } \\
(\text { minutes })\end{array}$ & $\begin{array}{c}\text { Area } \\
(\mathrm{mAu})\end{array}$ & $\begin{array}{c}\text { Height } \\
(\mathrm{mAu})\end{array}$ & $\begin{array}{c}\text { Peak Start } \\
(\text { minutes })\end{array}$ & $\begin{array}{c}\text { Peak End } \\
(\text { minutes })\end{array}$ \\
\hline Single injection & & & & & \\
\hline Standard nootkatone & 7.706 & 3602556 & 305434 & 7.093 & 8.352 \\
\hline Nootkatone suspected in whole-tuber & 8.006 & 2977185 & 235559 & 7.627 & 9.408 \\
\hline Spike injection & & & & & \\
\hline Standard nootkatone & 7.711 & 910096 & 82046 & 7.477 & 7.861 \\
\hline Nootkatone suspected in whole-tuber & 8.023 & 1535388 & 120572 & 7.861 & 9.109 \\
\hline
\end{tabular}


In this study, nootkatone was detected at a retention time of 7.706 minutes (Fig.-2B). Whereas the suspected compound to be nootkatone in extracts were detected at 8.006 minutes (Fig.-2C). Although the retention time was very close, it was likely that this compound was not a nootkatone. To confirmed this, spike injection was performed. The results of spike injection indicated that Peak-2 and Peak-3 were different compounds. Peak-2 that was nootkatone standard appeared at 7.711 minutes while the suspected as nootkatone compound in the extract appeared at 8.023 minutes (Fig.-2D).
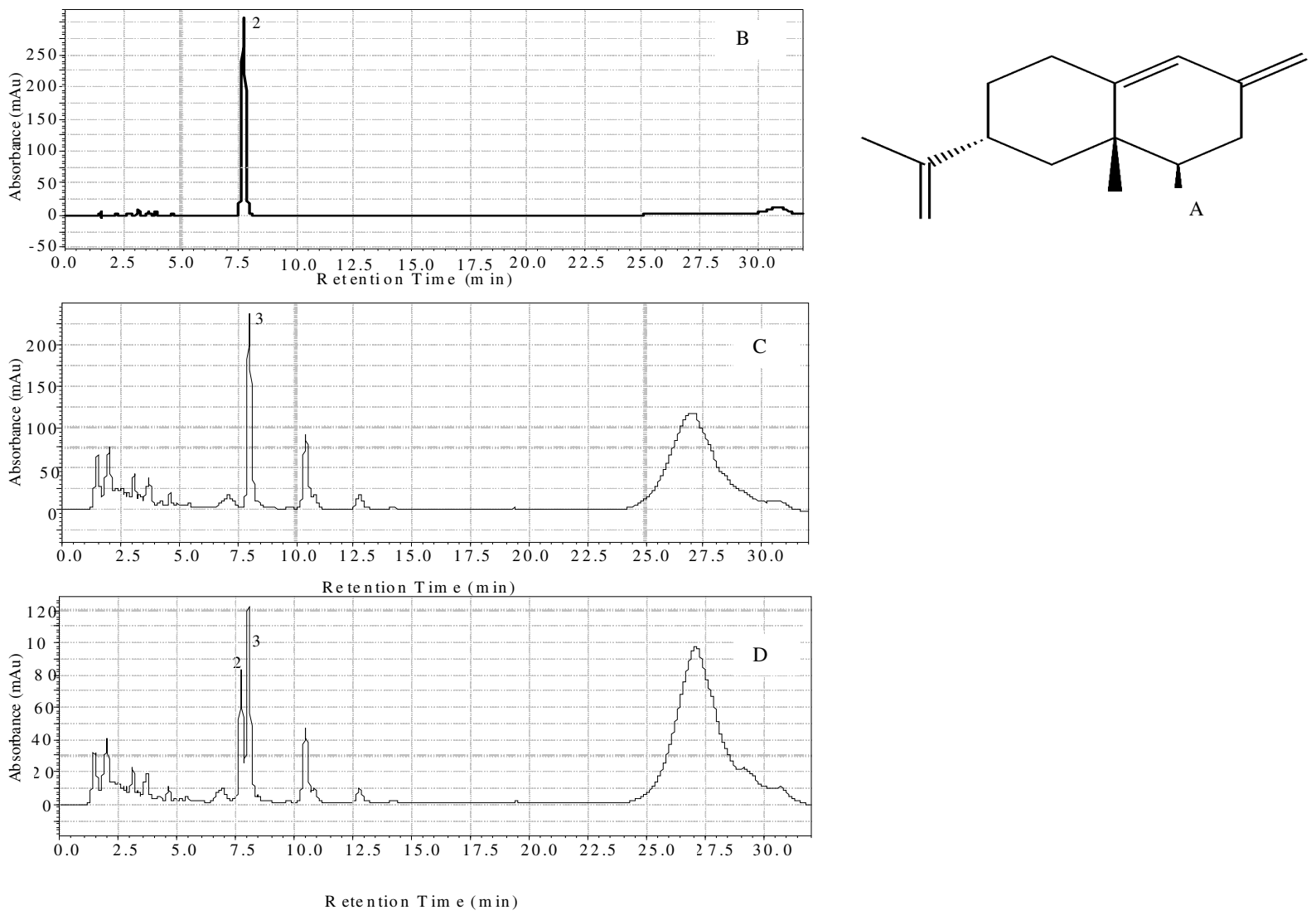

Fig.-2: (A) Chemical Structure of Nootkatone; The HPLC Chromatogram of (B) Nootkatone Standard; (C) Whole-

Tuber extract; (D) Spike injection of Nootkatone Standard and Whole-tuber extract; (2): Nootkatone; and (3)

Nootkatone suspected compound in Nutsedge's Tuber extract.

\section{CONCLUSION}

HPLC analysis showed that the peeled-tuber has the highest content of $\alpha$-cyperone that is $1.074 \%$, followed by the whole-tuber that is $0.736 \%$, and the lowest is the tuber's peel that is $0.202 \%$. Nootkatone was not found in any part of nutsedge tuber.

\section{ACKNOWLEDGMENT}

This study was supported by The Ministry of Research Technology and the Higher Education Republic of Indonesia from the PTUPT scheme with contract number 129/SP2H/PTNBH/DRPM/2018 which is lead by Dr. M.A. Chozin. The authors thank Indonesia Endowment Fund for Education (LPDP), the Ministry of Finance Republic of Indonesia for the financial support to Ferdhi Isnan Nuryana. Thanks also due to the Trop-BRC LPPM IPB to provide place and equipment for this research, also Laela Wulansari appreciated for her assistance to this research.

\section{REFERENCES}

1. R.K. Srivastava, A. Singh and S.V. Shukla, J. Biol. Act. Prod. Nat., 3(3), 166(2013)

2. C.T. Bryson and R. Carter, The Significance of Cyperaceae as Weeds, in: R.F.C. Naczi and B.A. 
RASĀYAN J. Chem.

Vol. 12 | No. 1 |360 - 365| January - March | 2019

Ford (Eds.), Sedges: Uses, Diversity, and Systematics of the Cyperaceae. Missouri Botanical Garden Press, Michigan, pp. 15-101 (2008).

3. A.K. Meena, A.K. Yadav, U.S. Niranjan, B. Singh, A.K. Nagariya and M. Verma, IJPCR., 2(1), 20 (2010).

4. N. Singh, B.R. Pandey, P. Verma, M. Bhalla and M. Gilca, Indian J. Nat. Prod. Resour., 3(4), 467 (2012).

5. M.A. Chozin, Y. Delsi, R. Saputra, N. Syarifi, S.A. Aziz and S. Zaman, In Proceeding of $24^{\text {th }}$ AsianPacific Weed Science Society Conference, Bandung, Indonesia, pp. 353-360 (2013).

6. M. Adfa, A.J. Kusnanda, W.D. Saputra, C. Banon, M. Efdi and M. Koketsu, Rasayan J. Chem., 10(4), 1088 (2017), DOI:10.7324/RJC.2017.1041866

7. T. Lim, Edible Medicinal and Non-Medicinal Plants Volume 10, Modified Stems, Roots, Bulbs. Springer, New York, p. 178-208 (2016), DOI:10.1017/978-94-017-7276-1

8. M.P. Rani and K.P. Padmakumari, J. Chromatogr. B. 904, 22 (2012), DOI:10.1016/j.jchromb.2012.05.042

9. A. M. Pirzada, H. H. Ali, M. Naeem, M. Latif, A. H. Bukhari and A. Tanveeer, J. Ethnopharmacol. 174, 540-560 (2015), DOI:10.1016/j.jep.2015.08.012

10. M. Mahfud, D. K. Y. Putri, Dewi and H. S. Kusuma, Rasayan J. Chem., 10(1), 86 (2017), DOI: 10.7324/RJC.2017.1011562

11. C. Kum, E. Kim, J. Kim, B. Lee, J. Min, J. Heo, J. Kim, M. Yeom, Y. Sohn and H. Jung, J. Ethnopharmacol, 205, 186(2017), DOI: 10.1016/j.jep.2017.03.017

12. J.C. Bede, P.E.A. Teal, W.G. Goodman and SS Tobe, Plant. Physiol., 127(2), 584(2001), DOI: 10.1104/pp.010264

13. K.K. Kumar and R.V. Nadh, Rasayan J. Chem., 4(3), 681(2010).

14. A.V. Kusuma, M.A. Chozin and D. Guntoro, J. Agron. Indonesia., 45(1), 100(2017), DOI: 10.24831/jai.v45i1.11842

15. F. Mojab, H. Vahidi, B. Nickavar and M. Kamali-Nejad, J. Med. Plants., 8 (32), 91(2009).

16. O. A. Lawal and A. O. Oyedeji, Molecules., 14(8), 2909(2009), DOI: 10.3390/molecules14082909

17. M. D. G. B. Zoghbi, E. H. A. Andrade, L. M. M. Carreira and E. A. S. Rocha, J. Essent. Oil Res. 20(1), 42 (2008), DOI:10.1080/10412905.2008.9699418

18. S. Kilani-Jaziri, W. Bhouri, I. Skandrani, I. Limem, L. Chekir-Ghedira and K. Ghedira, South African J. Bot., 77(3), 767(2011), DOI:10.1016/j.sajb.2011.03.015

19. R. H. Leonhardt and R.G. Berger, Adv. Biochem. Eng. Biotechnol., 123, 127(2014), DOI: 10.1007/10_2014_279

20. S. A. Dewi, M. A. Chozin and D. Guntoro, J. Agron. Indonesia., 45(1), 93(2017), DOI: 10.24831/jai.v45i1.12730

[RJC-5024/2019] 